\title{
Implementation of Village Staff Recruitment and Selection in Sidoarjo Regency
}

\section{Implementasi Rekrutmen dan Seleksi Perangkat Desa di Kabupaten Sidoarjo}

\author{
Eri Mega Selvia*, Isnaini Rodiyah \\ Universitas Muhammadiyah Sidoarjo
}

This study aims to analyze and describe the implementation of recruitment and selection of village officials in Sidoarjo Regency as well as supporting and inhibiting factors for the implementation of recruitment and selection of village officials in Sidoarjo Regency. The research method uses descriptive research with a qualitative approach. Data collection is done by observation, interviews, and documentation with informants. Data analysis techniques using the theory of Miles \& Huberman, namely data collection, data reduction, data presentation, and conclusions. The results showed that the implementation of the recruitment and selection of village officials in Sidoarjo Regency had been carried out in accordance with regulations where the registration and selection process was carried out in each village and the online selection process using a computer. The formation of the recruitment and selection committee for the village apparatus was carried out through a meeting led by the Village Head, but the condition of the facilities and infrastructure in the recruitment and selection of the village apparatus in the village was inadequate because

OPEN ACCESS

ISSN 2527-9246 (online)

ISSN 2338-445X (print)

Edited by:

Isna Fitria Agustina

Reviewed by:

Ismi Dwi Astuti Nurhaeni and Lely Indah Mindarti

*Correspondence: Eri Mega Selvia

erimegaselvia@umsida.ac.id

Published: 1 Maret 2020

Citation:

Selvia EM and Rodiyah I (2020) Implementation of Village Staff Recruitment and Selection in

Sidoarjo Regency.

JKMP (Jurnal Kebijakan dan

Manajemen Publik). 8:1.

doi: 10.21070/jkmp.v8i1.748 participants were required to bring their own laptops. Communication has been carried out well by the parties, namely through socialization. Supporting factors and obstacles to the implementation of recruitment and selection of village officials in Sidoarjo Regency, namely supporting factors consisting of SOPs have been implemented well. While the inhibiting factor is the implementation of the online selection of village equipment in Desa Kepambat having a schedule delay due to a server error. In addition, the facilities and infrastructure in Tulangan District are inadequate

Keywords: Implementation, Recruitment, Selection, Village Officials

\section{PENDAHULUAN}

Negara Republik Indonesia sebagai negara kesatuan menganut asas desentralisasi dalam penyelenggaraan pemerintahan daerah, berarti memberikan ruang demokrasi pada masyarakat yang ada di daerah. Dalam hal ini rakyat membentuk organisasi pemerintahannya sendiri selaras dengan berlandaskan koridor Peraturan Perundang-Undangan Negara dan pastinya sesuai kewenangan apa yang diserahkan oleh pusat. Berdasarkan Undang-Undang Nomor 23 Tahun 2014 yang telah disempurnakan dengan Undang-Undang Nomor 9 Tahun 2015 Tentang Pemerintah Daerah khusunya pasal 1 ayat 5 membuktikan semakin menguatkannya posisi daerah 
dalam upaya meningkatkan kemampuan disegala bidang, terutama kabupaten dan kota sebagai titik berat otonomi daerah. Tujuannya adalah mendekatkan pemerintah kepada publik yang dilayani hingga pada tatanan pemerintah desa. Agar dapat berhasil menuju pada kesejahteraan masyarakat dan dapat menciptakan sistem pemerintahan yang baik (good governance). Penyelenggaraan pemerintah desa, tidak bisa lepas dari perangkat desa yang mempunyai peran dalam mewujudkan tata pemerintahan yang baik. Hal tersebut menguatkan posisi perangkat desa yang sangat penting dalam membantu tugas dan kewenangan Kepala Desa Muslim and Nasution (2014) .

Mengingat begitu urgensi kiprah perangkat desa, maka sumber daya perangkat desa menjadi kata kunci dalam penyelenggaraan pemerintah desa, karena itu pengadaan personil perangkatnya perlu dilakukan seleksi yang ketat untuk memperoleh SDM berkualitas. Idealnya setelah proses rekrutmen, dilakukan baik di suatu instansi atau perusahaan. Rekrutmen dan seleksi akan berjalan efektif sebagaimana yang diharapkan yakni memperoleh aparatur yang berkualitas sesuai perencanaan SDM dan ANJAB (Analisis Jabatan). Kabupaten Sidoarjo melakukan seleksi calon perangkat desa menggunakan sistem dalam jaringan (daring) atau online guna menyeleksi perangkat desa untuk ditempatkan diseluruh desa di Kabupaten Sidoarjo. DPMDP3AKB terus mematangkan sistem tersebut. Seleksi secara daring diatur dalam Peraturan Bupati Nomor 55 Tahun 2016 Tentang Pedoman Pengangkatan dan Pemberhentian Perangkat Desa. Mekanisme seleksi termasuk materi tesnya berkoordinasi dengan pemerintahan desa terkait, pendaftarannya secara manual dan pelaksanaan tes bertempat di Badan Kepegawaian Nasional (BKN) secara online. Tes tidak dilakukan serentak, tergantung koordinasi antara kecamatan dengan pihak pemerintah desa masing- masing. Kepala desa juga menjadi ketua panitia seleksi, yang diharapkan dapat memberikan informasi terkait perekrutan, agar diperoleh calon perangkat desa yang berkompeten. Data keseluruhan 2017 lalu, yang akan berebut posisi perangkat desa se-Kabupaten Sidoarjo di 322 desa terdapat 950 calon perangkat desa.

Fenomena di lapangan yang ditemukan di Desa Kepadangan tersebut, masih menunjukkan banyak permasalahan terkait rekrutmen dan seleksi perangkat desa, yakni sebagai berikut: (1) ada perbedaan tersendiri mengenai tempat pelaksanaan seleksi, (2) adanya pengunduran jadwal pelaksanaan seleksi, serta (3) sarana dan prasarana yang belum memadai. Berdasarkan permasalahan yang terjadi, maka dari itu peneliti ingin meneliti implementasi rekrutmen dan seleksi perangkat desa di Kabupaten Sidoarjo.

\section{Implementasi Kebijakan Publik}

Implementasi merupakan proses umum tindakan administratif yang dapat diteliti pada tingkat program tertentu Grindle (1980). tindakan-tindakan yang dilakukan oleh pemerintah untuk mencapai tujuan yang telah ditetapkan dalam suatu keputusan kebijakan Edward (1980).

\section{Manajemen Sumber Daya Manusia}

Manajemen sumber daya manusia yaitu yang berkaitan dengan semua aspek tentang bagaimana orang kerja dan dikelola dalam organisasi. Ini mencakup kegiatan strategi SDM, manajemen SDM, tanggung jawab sosial perusahaan, manajemen pengetahuan, pengembangan organisasi, sumber-sumber SDM (perencanaan, rekrutmen dan seleksi) Armstrong (2009) .

\section{Rekrutmen dan Seleksi}

Rekrutmen adalah proses menarik orang-orang atau pelamar yang mempunyai minat dan kualifikasi yang tepat untuk mengisi posisi atau jabatan tertentu Marwansyah (2012). Sedangkan seleksi merupakan proses pemilihan dalam sekelompok pelamar yang paling memenuhi kriteria seleksi untuk posisi yang terdapat dalam sebuah perusahaan maupun suatu instansi Simamora (2012). 


\section{Perangkat Desa}

Berdasarkan Undang-Undang Nomor 6 Tahun 2014 tentang Desa Pasal 25 bahwa pemerintah desa kepala desa atau yang disebut dengan nama lain dan yang dibantu oleh perangkat desa atau yang disebut dengan nama lain. Perangkat desa adalah bagian dari pemerintah desa yang diangkat oleh kepala desa setelah dikonsultasikan dengan Camat atas nama Bupati/Walikota dan perangkat desa bertanggung jawab kepada kepala desa dalam membantu kepala desa dalam melaksanakan tugas dan wewenangnya.

\section{METODE PENELITIAN}

Menurut Sugiyono (2011) Penelitian ini menggunakan metode deskriptif dengan pendekatan kualitatif dikarenakan peneliti ingin mengetahui dan membuat deskripsi atau gambaran secara sistematis, faktual, dan akurat mengenai pola rekrutmen dan seleksi perangkat desa di Kabupaten Sidoarjo khususnya di Desa Kepadangan Kecamatan Tulangan.Penelitian ini berfokus pada implementasi Kebijakan Rekrutmen dan Seleksi Perangkat Desa di Kabupaten Sidoarjo yang meliputi : (a) Struktur birokrasi : (1) Standar Operasional Prosedur dan (2) Fragmentasi, (b) Sumber daya : (1) Staf, (2) Informasi, (3) Wewenang, dan (4) Fasilitas, (c) Disposisi : (1) Pengangkatan birokrasi dan (2) Insentif, dan (d) Komunikasi : (1) Transmisi, (2) Kejelasan, dan (3) Konsistensi serta faktor pendukung dan penghambat pelaksanaan pola rekrutmen dan seleksi perangkat desa di Desa Kepadangan Kec. Tulangan-Sidoarjo. Terdapat teknik penganalisisan data dilakukan yaitu dengan data reduction, data display, dan conclusion drawing/verification Miles (2009) .

\section{HASIL DAN PEMBAHASAN}

\section{Implementasi Rekrutmen dan Seleksi Perangkat Desa di Kabupaten Sidoarjo}

\section{Struktur Birokrasi}

Standar Operasional Prosedur dalam pelaksanaan rekrutmen dan seleksi perangkat desa di Kabupaten Sidoarjo telah dilaksanakan sesuai dengan regulasi yaitu mengacu pada Perbup Nomor 55 Tahun 2016 tentang Pedoman Pengangkatan dan Pemberhentian Perangkat Desa bahwa mekanisme pengangkatan pengangkatan perangkat desa terdiri dari : (1) Pembentukan panitia, (2) Penjaringan, (3) Penyaringan, dan (4) Pelantikan. Terdapat beberapa perubahan terkait tata cara pelaksanaan rekrutmen dan seleksi perangkat desa di Kabupaten Sidoarjo yang meliputi pendaftaran, penjaringan, dan seleksi. Dimana proses pendaftaran dan penjaringan dilaksanakan di masing-masing desa dan proses seleksinya secara online dengan menggunakan komputer. Pada Kecamatan Tulangan, pihak ketiga berasal dari UNESA.

Berdasarkan hasil penelitian di lapangan terdapat persamaan dengan judul Pola Rekrutmen Calon Legislatif Dapil 1 Provinsi Aceh yang Dilakukan oleh Partai Keadilan Sejahtera (PKS) dan Partai Nasional Demokrat (NASDEM) yaitu sama-sama membahas bahwa terdapat pola rekrutmen yang jauh berbeda namun memiliki tujuan yang sama yaitu untuk merekrut calon yang berkompeten di bidangnya. Jika dikaitkan dengan teori implementasi kebijakan publik telah sesuai bahwa fragmentasi merupakan penyebaran tanggungjawab suatu kebijakan kepada beberapa badan yang berbeda sehingga memerlukan koordinasi yang mengakibatkan menimbulkan konsekuensi pokok yang merugikan bagi keberhasilan implementasi kebijakan.

\section{Sumber Daya}

Pembentukan panitia rekrutmen dan seleksi perangkat desa dilakukan melalui musyawarah yang dipimpin oleh Kepala Desa dimana terdapat lima orang panitia dari BPD, perangkat Desa Kepadangan, dan tokoh masyarakat. Panitia dalam pelaksanaan rekrutmen dan seleksi perangkat desa merupakan orang yang memenuhi standar, memadai, dan berkompeten dan 
telah menjalankan tugasnya dengan baik terkait menyusun jadwal, membuat tata tertib, menyusun $\mathrm{RAB}$, menjaring bakal calon, menyeleksi, dan membuat berita acara bakal calon yang lolos

\section{Disposisi}

Tahap pengangkatan panitia rekrutmen dan seleksi perangkat desa dilatarbelakangi oleh akan adanya kekosongan jabatan, sehingga sebelum empat bulan jabatan perangkat desa habis, Kepala Desa mengadakan musyawarah untuk musyawarah desa dalam rangka pembentukan panitia penjaringan dan seleksi calon perangkat desa. Syarat yang harus dipenuhi untuk menjadi panitia yaitu berasal dari BPD, tokoh masyarakat, dan perangkat desa yang mengikuti musyawarah dan mendapat persetujuan dari Kepala Desa. Panitia memiliki dedikasi, tanggungjawab, dan disiplin kerja yang baik terhadap amanat yang dipegang karena telah bekerjasama dalam pelaksanaan penjaringan dan seleksi calon perangkat desa sehingga dapat berjalan dengan lancar.

Pelaksana dalam rekrutmen dan seleksi perangkat desa sudah baik karena taat terhadap tata tertib dan tugas panitia sudah transparan dan tidak dapat dimanipulasi. Rekrutmen dilakukan oleh panitia di desa sedangkan seleksi dilaksanakan di BKN. Panitia di masing-masing desa bertugas dalam menjaring calon perangkat desa, kemudian membuat edaran pengumuman bagi yang lolos administrasi di tahap 1 . Setelah itu panitia mendapat arahan untuk mengundang semua peserta yang lolos untuk mendapatkan arahan dari panitia di Kecamatan. Namun pihak Kecamatan dan panitia di desa setuju untuk tidak melakukan tes seleksi online di BKN sesuai anjuran dari DPMDPA3AKB Kabupaten Sidoarjo melainkan dilakukan di masing-masing desa di Kecamatan Tulangan.

\section{Komunikasi}

Penyaluran komunikasi yang pertama dalam implementasi rekrutmen dan seleksi perangkat desa yaitu panitia yang telah mendapatkan persetujuan dari Lurah mendapatkan undangan dari Kecamatan untuk mendapatkan sosialisasi dan pengarahan terkait implementasi rekrutmen dan seleksi perangkat desa dan membahas terkait server untuk pelaksanaan seleksi calon perangkat desa. Pihak DPMDP3AKB Kabupaten Sidoarjo adalah sebagai fasilitator yaitu menyampaikan, mensosialisasikan tentang kebijakan, dan regulasi yang baru, serta pihak ketiga yang ditunjuk. Pihak DPMDP3AKB Kabupaten Sidoarjo menawarkan dan memudahkan pihak desa dengan adanya BKN sehingga seleksi perangkat desa dapat terlaksana dengan lebih transparan. Pihak Desa hanya menunggu jadwal keluar dan tes seleksi secara online bagi peserta calon perangkat desa dilakukan di BKN secara gratis.

\section{Faktor Pendukung dan Penghambat Implementasi Rekrutmen dan Seleksi Perangkat Desa di Kabupaten Sidoarjo}

\section{Faktor Pendukung}

Faktor-faktor keberhasilan dalam pencapaian visi misi organisasi dipengaruhi oleh faktor internal dan faktor eksternal. Faktor eksternal dapat berupa adanya komitmen pemerintah yang seharusnya ada yang diwujudkan dalam berbagai kebijakan yang melibatkan masyarakat, antara lain:

\section{Standar Operasional Prosedur}

Standar Operasional Prosedur dalam implementasi rekrutmen dan seleksi perangkat desa sudah dilaksanakan dengan baik. Semua pihak yang terlibat saling bekerjasama tanpa terdapat perbedaan, selain itu tugas panitia menjadi lebih ringan dengan menggunakan seleksi. Pelaksanaan seleksi perangkat desa secara online menjadi lebih efektif dan transparan serta meminimalisir adanya money politic dibandingkan jika menggunakan sistem manual. 


\section{Komunikasi}

Faktor pendukung lainnya yaitu dengan saling menjaga komunikasi yang baik antara berbagai pihak yang terlibat yaitu panitia, Kepala Desa, dan pihak Kecamatan sebelum dan saat pelaksanaan, contohnya untuk mengetahui jadwal dan proses pelaksanaan. Selain itu panitia yang netral dalam melaksanakan rekrutmen dan seleksi perangkat desa sesuai dengan tupoksi dan tata tertib juga menjadi faktor pendukung karena seleksi online di Desa Kepadangan diselenggarakan di desanya sendiri, dimana tantangan yang mungkin terjadi adalah adanya titipan jabatan atau keluarga dari panitia, perangkat desa, atau kecamatan yang juga mengikuti seleksi perangkat desa di Desa Kepadangan. BKN sebagai tempat seleksi online yang ditunjuk dan direkomendasikan oleh DPMDP3AKB Kabupaten Sidoarjo memiliki kredibiltas yang tidak diragukan lagi dan selama pelaksanaan perekrutan ASN belum pernah terdapat catatan buruk tentang hasil kinerja dari BKN. Dimana fenomena tersebut dikaitkan.

\section{Faktor Penghambat}

\section{Sumber Daya}

Faktor penghambat lainnya yaitu dalam sumber daya pelaksanaan seleksi online perangkat desa di Desa Kepadangan mengalami pengunduran jadwal karena terjadi error server. Terdapat sarana dan prasarana implementasi rekrutmen dan seleksi perangkat desa di Kecamatan Tulangan yaitu peserta wajib membawa sendiri laptop untuk proses seleksi online dimana belum tentu semua peserta memiliki laptop, hal ini membuktikan bahwa Kecamatan Tulangan belum bisa memberikan fasilitas yang memadai bagi para peserta calon perangkat desa. Sehingga tidak menunjukkan kesesuaian dengan teori implementasi kebijakan publik yaitu bahwa fasilitas fisik yang mempunyai staf mencukupi, kapabel, dan kompeten, tetapi tanpa adanya fasilitas pendukung (sarana dan prasarana) untuk mencapai keberhasilan.

\section{Disposisi}

Faktor penghambat dalam implementasi rekrutmen dan seleksi perangkat desa yaitu dalam hal disposisi dimana Kecamatan Tulangan menyelenggarakan seleksi online di Desa masingmasing dan juga ada yang di UNESA, hal tersebut tidak sesuai dengan pihak DPMDP3AKB Kabupaten Sidoarjo yang memberikan rekomendasi untuk pelaksanaannya agar dilakukan di BKN. Sejak awal pihak ketiga yang ditunjuk oleh DPMDP3AKB Kabupaten Sidoarjo hanya BKN karena memiliki kerjasama. Selain itu pelaksanaan seleksi online di BKN lebih efektif, kompeten, dan memiliki kredibilitas yang diakui. Namun pelaksanaan seleksi onlinedi BKN membutuhkan koordinasi dengan pihak BKN di tingkat pusat dan dengan banyak pihak sehingga berpengaruh pada penentuan jadwal pelaksanaan Pihak Kecamatan dan panitia di desa setuju untuk tidak melakukan tes seleksi online di BKN.

\section{KESIMPULAN}

Implementasi rekrutmen dan seleksi perangkat desa di Kabupaten Sidoarjo pada dimensi struktur birokrasi telah dilaksanakan sesuai dengan regulasi. Pada dimensi sumber daya, pembentukan panitia rekrutmen dan seleksi perangkat desa dilakukan melalui musyawarah yang dipimpin oleh Kepala Desa namun kondisi sarana dan prasarana dalam pelaksanaan rekrutmen dan seleksi perangkat desa yang di desa belum memadai. Pada dimensi disposisi, panitia memiliki dedikasi tinggi terhadap amanat yang dipegang sehingga dapat berjalan dengan lancar. Pada dimensi komunikasi sudah dilaksanakan dengan baik oleh para pihak yaitu melalui sosialisasi. Faktor pendukung dan penghambat implementasi rekrutmen dan seleksi perangkat desa di Kabupaten Sidoarjo yaitu faktor pendukung terdiri dari Standar Operasional Prosedur dalam implementasi rekrutmen dan seleksi perangkat desa sudah dilaksanakan dengan baik. Sedangkan faktor penghambat yaitudalam sumber daya pelaksanaan seleksi online perangkat desa di Desa Kepadangan mengalami pengunduran jadwal karena terjadi error server. Selain itu, sarana dan prasarana implementasi rekrutmen dan seleksi perangkat desa di Kecamatan Tulangan belum memadai. 


\section{UCAPAN TERIMA KASIH}

Terima kasih kepada segenap Civitas Akademika Universitas Muhammadiyah Sidoarjo atas segala dukungan dan atensinya sehingga hasil penelitian ini dapat dipublikasikan menjadi jurnal ilmiah. Tidak lupa terima kasih kepada Redaksi JKMP yang telah menerbitkan Jurnal Ilmiah ini.

\section{REFERENCES}

Armstrong, M. (2009). and others (ed.) (United Kingdom: Kogan Page).

Edward, C. G. (1980). Implementing Public Policy (Washington DC:: Congressional Quartely Inc.), 1-8.

Grindle, M. (1980). Politics and Policy Implementation in The Third World (New Jersey: Princnton University Press).

Marwansyah (2012). Manajemen Sumber Daya Manusia Bandung (Bandung: Alfabeta).

Miles, M. B. . A. M. H. (2009). Analisis Data Kualitatif (Jakarta: UI-Press).

Muslim, N. and Nasution, D. I. (2014). Kinerja Aparat Desa dalam Penyelenggaraan Pemerintahan di Desa Pantai Labu Pekan. Jurnal Ilmu Pemerintahan dan Sosial Politik UMA.

Simamora, H. (2012). Manajemen Sumber Daya Manusia (Yogyakarta: STIE YKPN Yogyakarta).
Sugiyono (2011). Metode Penelitian Kuantitatif, Kualitatif, dan R\&D (Bandung: Alfabeta).

Conflict of Interest Statement: The authors declare that the research was conducted in the absence of any commercial or financial relationships that could be construed as a potential conflict of interest.

Copyright (c) 2020 Selvia and Rodiyah. This is an open-access article distributed under the terms of the Creative Commons Attribution License (CC BY). The use, distribution or reproduction in other forums is permitted, provided the original author(s) and the copyright owner(s) are credited and that the original publication in this journal is cited, in accordance with accepted academic practice. No use, distribution or reproduction is permitted which does not comply with these terms. 